\title{
OPTIMIZATION DECISION ON INFORMAL RECYCLING CHANNEL OF ELECTRIC VECHICLE BATTERIES AND SUPERVISION STRATEGY
}

\author{
GAO, H. - LIU, S. - GONG, D. ${ }^{*}-\mathrm{CAO}, \mathrm{G}$. \\ School of Economics and Management, Beijing Jiaotong University, 100044 Beijing, China \\ *Corresponding author \\ e-mail:dqgong@bjtu.edu.cn
}

(Received $8^{\text {th }}$ Mar 2019; accepted $1^{\text {st }}$ May 2019)

\begin{abstract}
In order to explore the impact of the government' regulatory strategy on the informal recycling channel of electric vehicle batteries, this paper compares and analyzes the evolutionary strategy of the government and the informal recycling channel of electric vehicle batteries group under fixed and dynamic punishment model. The results show that: (1) the dynamic system of replication under the fixed punishment model consists of four saddle points and one central point. The evolution process of the strategy is repetitive and periodic, and cannot reach equilibrium. (2) The dynamic system of replication under the dynamic punishment model consists of four saddle points and one focal point, and the stable Nash equilibrium can be achieved. That is to say, the optimized scenario is valid. (3) In order to improve the probability of the informal recycling channel of electric vehicle batteries choosing the transformation upgrading strategy, improving the legal environmental incomes after the transformation upgrading of the informal recycling channel of electric vehicle batteries group, and reducing the recycling cost of the available components extracted from the waste electric vehicle batteries through formal channels are effective approaches.
\end{abstract}

Keywords: dynamic punishment, evolutionary strategy, fixed punishment, recycling channel decision

\section{Introduction}

In recent years, environmental pollution, climate change and energy shortages have caused widespread concern in the world. One of the key factors in aggravating these problems is the transportation industry, which consumes a lot of energy and generates a lot of greenhouse gases (Gong et al., 2019). In order to protect national energy security, alleviate fuel supply conflicts, reduce exhaust emissions, and improve the atmospheric environment, China has proposed a national strategy to vigorously develop new energy vehicles (Zhao et al., 2016). In 2016, China's new energy vehicle sales reached 777,000 units, with a total promotion of more than 1.7 million units, accounting for more than $50 \%$ of the global new energy vehicle market. The rapid development of new energy vehicles has also brought about some new problems. It is predicted that the number of power battery scraps will exceed 500,000 tons by 2020, about 20 times the amount recorded in 2016. The contradiction between the development of pure electric vehicle industry and the resource environment is becoming more and more prominent ( $\mathrm{Li}$ et al., 2014). If the waste power battery is not properly disposed, the potential harmful substances contained in it will cause environmental pollution (Ordoñez et al., 2016). On the other hand, lithium, cobalt, copper and aluminum in the scrapped power battery are recyclable materials, which have extremely high recovery value (Xu et al., 2008; Tan et al., 2015). In fact, China's power battery recycling rate is low. In 2016, China's waste power battery recycling amount was less than 10,000 tons, and the recovery rate was less than $20 \%$. If the power battery recovery rate is still at the current low level, there 
will be a large number of used power batteries flowing into private small workshops or abandoned, posing great threat to the ecological environment.

At present, research on used power batteries focuses on the status of recycling, recycling models and the impact of government environmental regulations on recycling strategies. China's recycling process for power batteries is still in the exploratory stage, and recycling technology aiming at recycling manufacturing has not been carried out (Yu et al., 2014). There are no specific measures and equipment guarantees for the production safety and environmental issues involved in the recycling of lithium-ion batteries (Gu et al., 2017). Scholars have done a lot of research on the recycling mode of closed-loop supply chain, for example, Savaskan et al.(2004) considered a decentralized model and a centralized model of a monopolist manufacturer and a retailer, compared and analyzed three modes of manufacturer recycling, retailer recycling and third-party recycling. They found that retailer recycling was the most efficient way. Savaskan et al. (2006) studied the recycling problem from the perspective of the manufacturer's benefit and found that in the homogeneous market, if the competition between retailers is fierce, the manufacturer will adopt the direct recycling model; otherwise, the retailer recycling model will be adopted. De Giovanni et al. (2014) established a two-cycle closed-loop supply chain game model of a monopolist manufacturer and a retailer, and analyzed the corporate, environmental and social benefits of the three modes of manufacturer recycling, retailer recycling and third-party recycling through numerical examples. It was pointed out that only in a small scope, manufacturers outsourcing their recycling business can contribute to corporate, environmental and social benefits. The research on the decision-making problem of power battery recovery mode is still in the initial stage. Liu and Gong (2014) studied the matching behavior of vehicles and batteries in the retailer recycling mode, and analyzed the influencing factors of recycling and the influence degree of various factors. Turner et al. (2016) analyzed and compared of EPR (Extended Producer Responsibility) and EOL (End of life) on recovery rate, recovery efficiency, management cost, etc., and concluded that the effective implementation of EPR is more conducive to the recycling of power batteries. Hong and Yeh (2012) comparative analyzed of retailer recycling and third-party recycling models revealed that retailer recycling models were more effective when third parties are non-profit organizations. Ma et al. (2016) studied on WEEE closed-loop supply chain decision-making problem of mixed channel sales/recycling under government regulation. As China's power battery recycling system is still not perfect, environmental pollution and resource waste in the recycling process are very serious, which will adversely affect the development of the industry (Han et al., 2016). China has no specific legislation on the recycling of new energy vehicle power batteries, and the healthy and sustainable development of the scrapped power battery recycling industry has been restricted (Han et al., 2017). Therefore, the recycling industry is still in the early stages of development, and government intervention is required at this time (Capon et al., 2015). Zhang et al. (2016) pointed out that incentives such as recycling regulatory policies and subsidies are not perfect, resulting in many enterprises power battery recycling interest is very low. Wang and $\mathrm{Wu}$ (2017) pointed out that the nonmandatory policy has caused battery manufacturers and OEMs not to plan battery recycling. Wang et al. (2014) studied the effects of four subsidy policy schemes, including direct subsidies, recycling subsidies, research and development subsidies and product subsidies on the recycling of auto parts (Wang et al., 2014; Du et al., 2018). Li 
and $\mathrm{Mu}$ (2018) analyzed the impact of subsidized $4 \mathrm{~S}$ stores, OEMs and battery manufacturers on recycling efficiency.

Through the above literature, it is found that there are few studies on the relevant regulatory policies for power battery recycling and the recycling targets are mainly based on formal recycling group. In fact, more than $80 \%$ of used power batteries in China have flowed into the informal recycling group. Such groups are spontaneously driven by economic interests, and formal recycling companies lack competitiveness in terms of cost and price. In addition, it is impossible for the government and the informal recycling group to have sufficient information. The two sides cannot be completely rational, and the decisions made can only be completed under bounded rational conditions. Moreover, the government's regulation of recycling vendors is also in its infancy. How the government's incentives for formal and informal recyclers evolved and how the informal recycling community should decide is worth studying.

How to effectively supervise the power recycling industry has become an urgent problem to be solved in the development of circular economy. At present, this issue has not attracted enough attention. The research on reverse recycling of power battery also pays little attention to the informal recycling group. Based on the bounded rationality hypothesis and using the relevant theory of evolutionary game, this paper studies the dynamic game relationship between the informal recycling channel of electric vehicle batteries and the government, and analyzes the stability of different strategies and proposes corresponding management enlightenment.

\section{Evolutionary game model}

\section{Model assumptions and description}

(1) It is assumed that the participants in the game include the government and the informal recycling channel of electric vehicle batteries, and the two sides of the game are bounded rational.

(2) The informal recycling channel of electric vehicle batteries group consists of $n$ informal recyclers, assuming that $\mathrm{n}$ informal recyclers are independent of each other.

(3) There are only two strategies for the government and the informal recycling channel of electric vehicle batteries to participate in the game. The strategies available to the government are \{positive regulation, negative regulation\}. Positive regulation means the government's punishment measures or subsidy policies for different recycling behaviors of informal recycling channel. Negative regulation means that the government regulatory departments do not supervise and regulate the informal recycling channel groups of electric vehicle batteries. The informal recycling channel groups of electric vehicle batteries have two recycling strategies, the strategies are \{transformation upgrading, non-transformation upgrading\}. Transformation upgrading strategy means that the informal recycling group of electric vehicle batteries is upgraded into a legal and regular recycling group through technology upgrade, and the nontransformation upgrading strategy means that the informal recycling group of power battery continues to be lucky to recycle through informal recycling channels.

(4) Suppose that the probability of the government choosing the positive regulation strategy is $\mathrm{x}$ and the probability of the negative regulation is $1-\mathrm{x}$, meanwhile, the probability of the informal recycling channel of electric vehicle batteries choosing the transformation upgrading strategy is $\mathrm{y}$, and the probability of the non-transformation upgrading strategy is $1-\mathrm{y}$. 
(5) The cost and benefit parameters are assumed and explained as follows: $C$ is the recycling cost of the power waste battery that can be utilized without disassembly; $C_{1}$ and $C_{2}$ are the recycling cost of the available components extracted from the waste electric vehicle batteries through formal channels and informal channels; $C_{3}$ is the governance cost that the government needs to pay due to environmental pollution when the informal recyclers choose non-transformation upgrading strategies; $\alpha$ is the proportion of the part of the electric vehicle batteries that does not need to be dismantled; $R_{1}$ and $R_{2}$ are illegal and legal environmental incomes before and after the transformation upgrading of the informal recycling channel of electric vehicle batteries group; $R_{3}$ is the social benefit that the government receives when the informal recycling channel of electric vehicle batteries group choose the transformation upgrading strategy and the government choose the positive regulation strategy; the informal recycling channel of electric vehicle batteries group will receive subsidies from the government when choosing the transformation upgrading strategy, and the subsidy is $G$; if the informal recycling channel of electric vehicle batteries group chooses the nontransformation upgrading, the probability of being discovered by the government is $\varepsilon$, and the punishment of $p$ is obtained.

According to the above model description and assumptions, the payoff matrix of the government and the informal recycling channel of electric vehicle batteries group evolution game is shown in Table 1.

Table 1. Payoff matrix between the government and the informal recycling channel of electric vehicle batteries group

\begin{tabular}{|c|c|c|c|}
\hline \multirow{2}{*}{\multicolumn{2}{|c|}{ The game }} & \multicolumn{2}{|c|}{ The informal recycling channel of electric vehicle batteries group } \\
\hline & & Transformation upgrading (y) & Non-transformation upgrading (1-y) \\
\hline \multirow{2}{*}{ The government } & $\begin{array}{l}\text { Positive } \\
\text { regulation }(\mathrm{x})\end{array}$ & $\begin{array}{c}R_{3}-G \\
n R_{1}-n \alpha C-n(1-\alpha) C_{1}+G\end{array}$ & $\begin{array}{c}R_{3}-C_{3}+\varepsilon n p \\
n R_{2}-n \alpha C-n(1-\alpha) C_{2}-\varepsilon n p\end{array}$ \\
\hline & $\begin{array}{l}\text { Negative } \\
\text { regulation (1-x) }\end{array}$ & $\begin{array}{c}0 \\
n R_{1}-n \alpha C-n(1-\alpha) C_{1}\end{array}$ & $\begin{array}{c}-C_{3} \\
n R_{2}-n \alpha C-n(1-\alpha) C_{2}\end{array}$ \\
\hline
\end{tabular}

\section{The model}

According to the payoff matrix of the government and the informal recycling channel of electric vehicle batteries group evolution game in Table 1, we assume that the expected return of the government's positive regulation strategy is $E_{11}$, the expected return of negative regulation strategy is $E_{12}$, and the average expected return of the group is $E_{1}$, then we can obtain Equations 1-3.

$$
\begin{gathered}
E_{11}=x\left(R_{3}-G\right)+(1-x)\left(R_{3}-C_{3}+\varepsilon n p\right) \\
E_{12}=x \times 0+(1-x) \times-C_{3} \\
E_{1}=y E_{11}+(1-y) E_{12}
\end{gathered}
$$


Meanwhile, we assume that the expected return of informal recycling channel of electric vehicle batteries group's transformation upgrading strategy is $E_{21}$, the expected return of non-transformation upgrading strategy is $E_{22}$, and the average expected return of the group is $E_{2}$, then we can obtain Equations 4-6.

$$
\begin{gathered}
E_{21}=y\left(n R_{1}-n \alpha C-n(1-\alpha) C_{1}+G\right)+(1-y)\left(n R_{1}-n \alpha C-n(1-\alpha) C_{1}\right) \\
E_{22}=y\left(n R_{2}-n \alpha C-n(1-\alpha) C_{2}-\varepsilon n p\right)+(1-y)\left(n R_{2}-n \alpha C-n(1-\alpha) C_{21}\right) \\
E_{2}=x E_{21}+(1-x) E_{22}
\end{gathered}
$$

The complex dynamic equation is actually a dynamic differential equation that describes the frequency or frequency of a particular strategy being used in a population (Friedman, 1991, 1998). So the replication dynamic equation of the government and the informal recycling channel of electric vehicle batteries group evolution game is in the form of Equation 7.

$$
\left\{\begin{array}{l}
\frac{d x}{d t}=x(1-x)\left[n R_{1}-n R_{2}-n(1-\alpha)\left(C_{1}-C_{2}\right)+y(G+\varepsilon n p)\right] \\
\frac{d y}{d t}=y(1-y)\left[R_{3}+\varepsilon n p-x(G+\varepsilon n p)\right]
\end{array}\right.
$$

The Jacobian matrix of the evolutionary system of the government and the informal recycling channel of electric vehicle batteries group is in the form of Equation 8.

$$
J=\left|\begin{array}{cc}
(1-2 x)\left[n R_{1}-n R_{2}-n(1-\alpha)\left(C_{1}-C_{2}\right)+y(G+\varepsilon n p)\right] & x(1-x)(G+\varepsilon n p) \\
y(1-y)[-x(G+\varepsilon n p)] & (1-2 y)[R+\varepsilon n p-x(G+\varepsilon n p)]
\end{array}\right|
$$

\section{Analysis of equilibrium point of evolutionary game}

In order to make the revenue of the government and the informal recycling channel of electric vehicle batteries group more consistent with the reality, this paper considers the following situation: when the government chooses a positive regulation strategy, due to the existence of subsidies and penalties, the benefits of the transformation upgrading of power battery recycling enterprises will be greater than the benefits of non-transformation upgrading; similarly, when the informal recycling channel of electric vehicle batteries group chooses a non-transformation upgrading strategy, the benefits of the positive regulation of the government will be greater than the benefits of the negative regulation. Therefore the following inequalities can be obtained (see Eq. 9).

$$
\left\{\begin{array}{l}
0<n R_{2}-n R_{1}-C_{3}+n\left(C_{2}-C_{1}\right)<(G+\varepsilon n p) \\
0<R_{3}+\varepsilon n p<G+\varepsilon n p
\end{array}\right.
$$

Therefore, the five Nash equilibrium points of the dynamic evolution of the government and the informal recycling channel of electric vehicle batteries group 
systems are $(0,0),(1,0),(1,1),(0,1)$ and $\left(x^{*}, y^{*}\right)$, where $x^{*}=\left[n R_{2}-n R_{1}-n(1-\alpha)\left(C_{2}-C_{1}\right)\right] /(G+\varepsilon n p), y^{*}=\left(R_{3}+\varepsilon n p\right) /(G+\varepsilon n p)$. The stability of the five equilibrium points is analyzed by D. Friedman's method for determining the equilibrium point. The analysis results of the five equilibrium points are shown in Table 2.

Table 2. Stability of the dynamic evolution of the government and the informal recycling channel of electric vehicle batteries group evolution

\begin{tabular}{c|c|c|c}
\hline Equilibrium point & $\operatorname{Det}(\mathbf{J})$ & $\operatorname{Tr}(\mathbf{J})$ & stability \\
\hline$(0,0)$ & - & Uncertain & Saddle point \\
$(1,0)$ & - & Uncertain & Saddle point \\
$(1,1)$ & - & Uncertain & Saddle point \\
$(0,1)$ & - & Uncertain & Saddle point \\
$\left(x^{*}, y^{*}\right)$ & - & 0 & Center point \\
\hline
\end{tabular}

According to the above analysis, the stability of the stability point of the evolutionary game model between the government and the informal recycling channel of electric vehicle batteries group are: the evolutionary state of points $(0,0),(1,0),(1,1)$ and $(0,1)$ are saddle point, and the evolutionary state of point $\left(x^{*}, y^{*}\right)$ is center point. Since the value of the real part of the feature root corresponding to the center point is zero, we know that $\left(x^{*}, y^{*}\right)$ is the equilibrium point, but it is not the stable point of evolution. The evolutionary trajectory of the government and the informal recycling channel of electric vehicle batteries group is a closed loop curve without $\left(x^{*}, y^{*}\right)$. Due to the choice of the initial strategy of both parties and the disturbance in the evolution process, the development of the system will have a certain randomness, which will have a greater impact on environmental protection and social harmony, and also make the management of the government very difficult. The system does not have an evolutionary stability strategy, which may be one of the important reasons why the informal recycling channel of electric vehicle batteries group chooses not to upgrade and lead to environmental pollution.

\section{Optimization model of the evolutionary game}

\section{The optimization model}

Based on the content of the previous section, we know that the evolutionary behavior of the government and the informal recycling channel of electric vehicle batteries group games under fixed punishment. In fact, in the process of evolutionary game between the two sides, different punishments should be applied to the specific fraudulent behaviors adopted by the informal recycling channel of electric vehicle batteries group. The punishment measures at this time can be called dynamic punishment mechanisms. It is assumed that the punishment measures adopted by the government are directly proportional to the degree to which the informal recycling channel of electric vehicle batteries group adopts a non-transformation upgrading strategy, that is, the punishment value received by the informal recycling channel of electric vehicle batteries group at 
this time is changed from $p$ to dynamic $g(y)=(1-y) q$, where $q$ indicates the maximum degree of punishment. After the dynamic punishment measures are taken, the game payoff matrix between the government and the informal recycling channel of electric vehicle batteries group under dynamic punishment mechanism is shown in Table 3.

Table 3. Payoff matrix between the government and the informal recycling channel of electric vehicle batteries group under dynamic punishment mechanism

\begin{tabular}{l|c|c|c}
\hline \multicolumn{2}{c|}{ The game } & \multicolumn{2}{|c}{ The informal recycling channel of electric vehicle batteries group } \\
\cline { 2 - 4 } & $\begin{array}{c}\text { Transformation upgrading (y) } \\
\text { The government } \\
\text { regulation (x) }\end{array}$ & $\begin{array}{c}R_{3}-G \\
n R_{1}-n \alpha C-n(1-\alpha) C_{1}+G\end{array}$ & $\begin{array}{c}\text { Non-transformation upgrading (1-y) } \\
n R_{3}-C_{3}+\varepsilon n g(y)\end{array}$ \\
\cline { 2 - 4 } & $\begin{array}{c}\text { Negative } \\
\text { regulation (1-x) }\end{array}$ & $\begin{array}{c}0 \\
n R_{1}-n \alpha C-n(1-\alpha) C_{1}\end{array}$ & $n R_{2}-n \alpha C-n(1-\alpha) C_{2}-\varepsilon n g(y)$ \\
\hline
\end{tabular}

Based on Table 3, we analyze the evolution stability of the government and the informal recycling channel of electric vehicle batteries group under dynamic punishment mechanism. Similar to the fixed punishment mechanism, the dynamic replication equation of the game between the two sides under the dynamic punishment mechanism is in the form of Equation 10.

$$
\left\{\begin{array}{l}
\frac{d x}{d t}=x(1-x)\left[n R_{1}-n R_{2}-n(1-\alpha)\left(C_{1}-C_{2}\right)+y(G+\varepsilon n g(y))\right] \\
\frac{d y}{d t}=y(1-y)\left[R_{3}+\varepsilon n g(y)-x(G+\varepsilon n g(y))\right]
\end{array}\right.
$$

\section{The equilibrium point after optimization}

The Nash equilibrium points of the dynamic evolution of the government and the informal recycling channel of electric vehicle batteries group systems under dynamic punishment mechanism are $(0,0),(1,0),(1,1),(0,1)$ and $\left(x^{* *}, y^{* *}\right)$, where $x^{* *}=\left[n R_{2}-n R_{1}-n(1-\alpha)\left(C_{2}-C_{1}\right)\right] /(G+\varepsilon n g(y)), y^{* * *}=\left(R_{3}+\varepsilon n g(y)\right) /(G+\varepsilon n g(y))$. The Jacobian matrix of the evolutionary system of the two sides is in the form of Equation 11.

$$
J_{1}=\left|\begin{array}{cc}
(1-2 x)\left[n R_{1}-n R_{2}-n(1-\alpha)\left(C_{1}-C_{2}\right)+y(G+\varepsilon n g(y))\right] & x(1-x)(G+\varepsilon n g(y)) \\
y(1-y)[-x(G+\varepsilon n g(y))] & (1-2 y)[R+\varepsilon n g(y)-x(G+\varepsilon n g(y))]
\end{array}\right|
$$

The analysis conditions under the dynamic punishment mechanism are similar to the fixed punishment model, that is, see Equation 12.

$$
\left\{\begin{array}{l}
0<n R_{2}-n R_{1}-n(1-\alpha)\left(C_{2}-C_{1}\right)<(G+\varepsilon n g(y)) \\
0<R_{3}+\varepsilon n g(y)<G+\varepsilon n g(y)
\end{array}\right.
$$


According to the calculation, the value of the matrix of the determinant corresponding to points $(0,0),(1,0),(1,1)$ and $(0,1)$ are negative, we know that points $(0,0),(1,0),(1,1)$ and $(0,1)$ are saddle points. Substituting point $\left(x^{* *}, y^{* *}\right)$ into formula (11), we can get that the characteristic root of $\left(x^{* *}, y^{* *}\right)$ is a bunch of characteristic negative roots with negative real parts. Point $\left(x^{* *}, y^{* *}\right)$ is the focus of evolutionary stability, and the state of system evolution has asymptotic stability, see Table 4.

Table 4. Stability of the dynamic evolution of the government and the informal recycling channel of electric vehicle batteries group evolution under dynamic punishment mechanism

\begin{tabular}{c|c|c|c}
\hline Equilibrium point & Det $(\mathbf{J})$ & $\operatorname{Tr}(\mathbf{J})$ & stability \\
\hline$(0,0)$ & - & Uncertain & Saddle point \\
$(1,0)$ & - & Uncertain & Saddle point \\
$(1,1)$ & - & Uncertain & Saddle point \\
$(0,1)$ & - & Uncertain & Saddle point \\
$\left(x^{* *}, y * *\right)$ & - & 0 & Stable point \\
\hline
\end{tabular}

Similar to the analysis of evolutionary stability in fixed punishment model, we know that $\left(x^{* *}, y^{* *}\right)$ is the stable equalization point of the system evolution. We can get $x^{* *}, y^{* *}$ as Equation 13 .

$$
x^{* *}=\frac{n R_{2}-n R_{1}-n(1-\alpha)\left(C_{2}-C_{1}\right)}{G+\varepsilon n g\left(y^{* *}\right)}, y^{* * *}=\frac{R_{3}+\varepsilon n g\left(y^{* * *}\right)}{G+\varepsilon n g\left(y^{* *}\right)}
$$

According to Equation 13, we can get $x^{* *}, y^{* *}$ as Equation 14.

$$
x^{* *}=\frac{2\left[n R_{2}-n R_{1}-n(1-\alpha)\left(C_{2}-C_{1}\right)\right]}{G+\sqrt{G^{2}+4\left(G-R_{3}\right) \varepsilon n q}}, y^{* *}=1+\frac{G-\sqrt{G^{2}+4\left(G-R_{3}\right) \varepsilon n q}}{2 \varepsilon n q}
$$

According to Equation 14, we analyze the influence of the main parameters on the evolutionary equilibrium under the dynamic punishment model. The results of the analysis are as follows:

(1) According to $x * *$, we can get that: $d x * / d n>0, d x * * / d R_{2}>0, d x * * / d C_{2}>0$, $d x * * / d R_{1}<0, \quad d x * * / d C_{1}<0, d x * * / d \alpha<0, d x * * / d G<0, d x * * / d R_{3}>0, d x * * / d R_{3}>0$, $d x * * / d q<0, d x * * / d \varepsilon<0$.

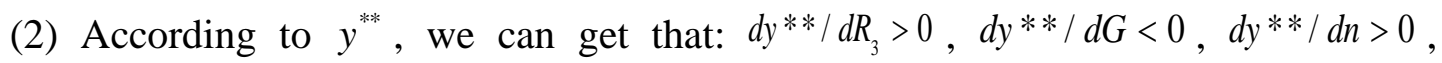
$d y * * / d \varepsilon>0, d y * * / d q>0$.

Based on the above analysis, we can get the following conclusion: (1) Number of the informal recycling channel of electric vehicle batteries, the probability of being discovered by the government when the informal recycling channel of electric vehicle batteries group chooses the non-transformation upgrading, the social benefit that the 
government receives when the informal recycling channel of electric vehicle batteries group choose the transformation upgrading strategy and the government choose the positive regulation strategy, the maximum degree of punishment and the subsidy when the informal recycling channel of electric vehicle batteries group choose the transformation upgrading strategy will affect the size of $x^{* *}$ and $y^{* *}$.

(2) When $q$ and $\varepsilon$ increase, $x^{* *}$ will decrease, and $y^{* *}$ will increase, indicating that the probability that the informal recycling channel of electric vehicle batteries choose the strategic probability of transformation upgrading will increase, and the probability that the government choose the strategic probability of positive regulation will decrease. $R_{3}, G$ and $\mathrm{n}$ have the same effect on the changing trend of $x^{* *}$ and $y^{* *}$.

(3) For the government, improving the legal environmental incomes after the transformation upgrading of the informal recycling channel of electric vehicle batteries group, and reducing the recycling cost of the available components extracted from the waste electric vehicle batteries through formal channels can reduce the probability of the government taking positive regulation strategy.

\section{Numerical analysis}

We first analyze the evolutionary game between the government and the informal recycling channel of electric vehicle batteries group under the fixed punishment model, the results of the analysis are shown as follows:

\section{The results under the fixed punishment model}

When

$$
0<n R_{2}-n R_{1}-n(1-\alpha)\left(C_{2}-C_{1}\right)<(G+\varepsilon n g(y))
$$

$0<R_{3}+\varepsilon n g(y)<G+\varepsilon n g(y)$, the initial probability of the government choosing the positive regulation strategy is $\mathrm{x}=0.2$, and the initial probability of the informal recycling channel of electric vehicle batteries group choosing transformation upgrading strategy is $y=0.6$. The evolutionary game process of the mixed strategy under the fixed punishment mechanism can be shown in Figure 1.

It can be seen from Figure 1 that the evolution process between the government and the informal recycling channel of electric vehicle batteries group under the fixed punishment model is a closed-loop curve with a center cycle. At this time, the game process of both parties is periodic behavior, and there is no stable point.

(2) When $0<n R_{2}-n R_{1}-n(1-\alpha)\left(C_{2}-C_{1}\right)<(G+\varepsilon n g(y))$ and $0<R_{3}+\varepsilon n g(y)<G+\varepsilon n g(y)$, the initial probability of the government choosing the positive regulation strategy is $\mathrm{x}=0.2$, and the initial probability of the informal recycling channel of electric vehicle batteries group choosing transformation upgrading strategy is $y=0.2$ and $y=0.6$, respectively. The evolutionary game process of the strategy that the informal recycling channel of electric vehicle batteries group transformation upgrading strategy under different initial probabilities under the fixed punishment model can be shown in Figure 2.

It can be seen from Figure 2 that the informal recycling channel of electric vehicle batteries group transformation upgrading strategy under the fixed punishment model presents a state of fluctuation, and the fluctuation state is related to the initial probability of the government's strategy, and the fluctuation is larger when the initial strategy of the government's positive regulation is low. 


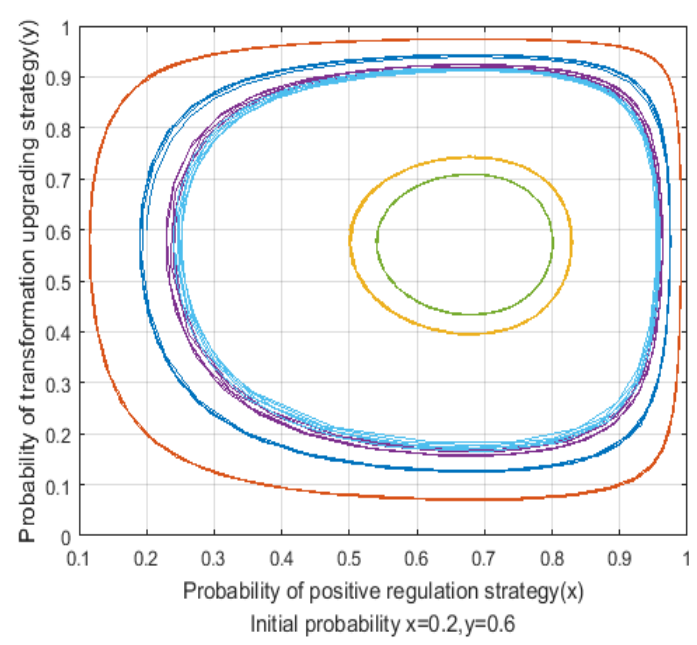

Figure 1. Hybrid strategy evolution process of the government and the informal recycling channel of electric vehicle batteries group under fixed punishment model

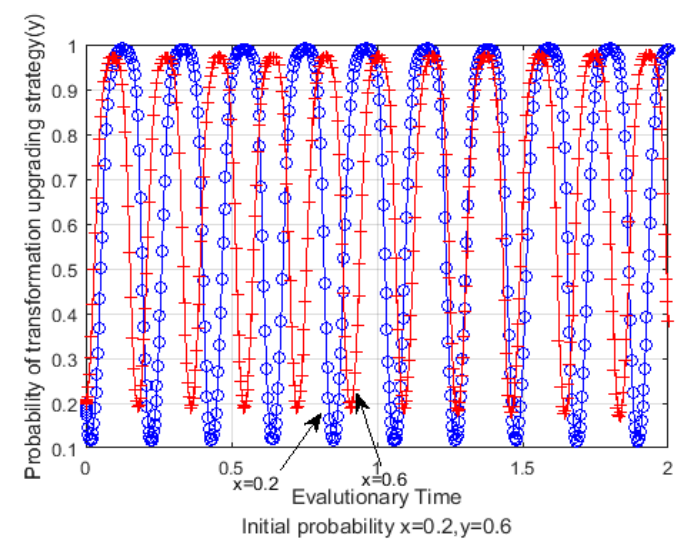

Figure 2. Evolution process of the informal recycling channel of electric vehicle batteries group's strategy under different initial probabilities under fixed punishment model

Then we analyze the evolutionary game between the government and the informal recycling channel of electric vehicle batteries group under the dynamic punishment mechanism, the results of the analysis are shown as follows:

\section{The results under the dynamic punishment model}

$$
\text { When }
$$

$$
0<n R_{2}-n R_{1}-n(1-\alpha)\left(C_{2}-C_{1}\right)<(G+\varepsilon n g(y))
$$

and

$0<R_{3}+\varepsilon n g(y)<G+\varepsilon n g(y)$, the initial probability of the government choosing the positive regulation strategy is $\mathrm{x}=0.2$, and the initial probability of the informal recycling channel of electric vehicle batteries group choosing transformation upgrading strategy is $y=0.6$. The evolutionary game process of the mixed strategy under the dynamic punishment model can be shown in Figure 3.

It can be seen from Figure 3 that although the evolution process between the government and the informal recycling channel of electric vehicle batteries group under dynamic penalty model fluctuates, the system will finally converge to the central point, 
indicating that the introduction of dynamic punishment model, can gradually stabilize the evolution of the two sides.

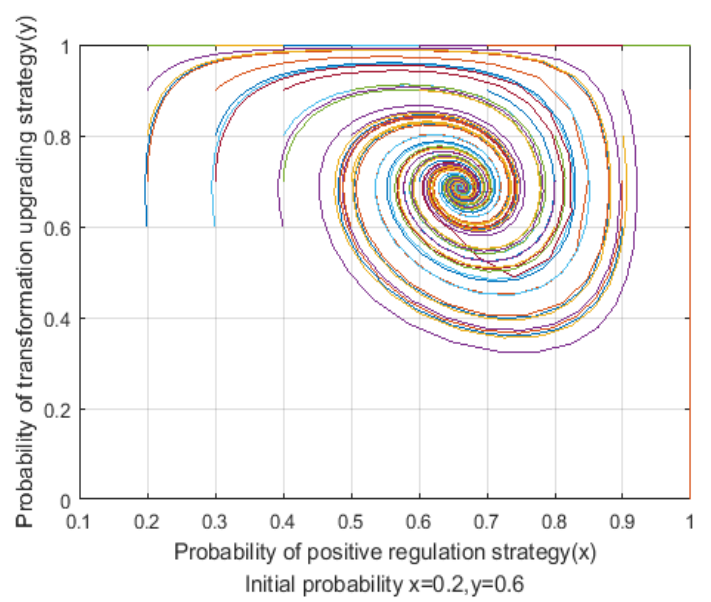

Figure 3. Hybrid strategy evolution process of the government and the informal recycling channel of electric vehicle batteries group under dynamic punishment model

When

$$
0<n R_{2}-n R_{1}-n(1-\alpha)\left(C_{2}-C_{1}\right)<(G+\varepsilon n g(y))
$$

and

$0<R_{3}+\varepsilon n g(y)<G+\varepsilon n g(y)$, the initial probability of the government choosing the positive regulation strategy is $\mathrm{x}=0.2$, and the initial probability of the informal recycling channel of electric vehicle batteries group choosing transformation upgrading strategy is $y=0.2$ and $y=0.6$, respectively. The evolutionary game process of the strategy that the informal recycling channel of electric vehicle batteries group transformation upgrading strategy under different initial probabilities under the dynamic punishment model can be shown in Figure 4.

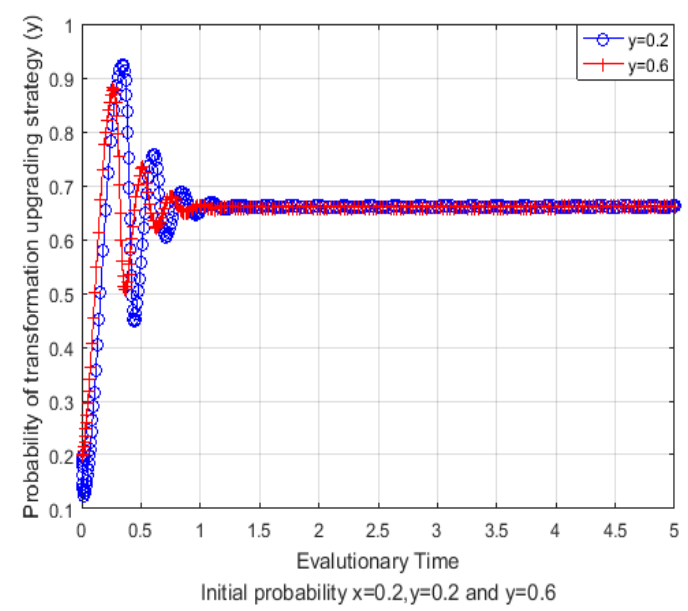

Figure 4. Hybrid strategy evolution process of the government and the informal recycling channel of electric vehicle batteries group under dynamic punishment model

It can be seen from Figure 4 that the strategy of the informal recycling channel of electric vehicle batteries group choose transformation upgrading under the dynamic 
punishment model presents a state of volatility. Although the initial stage shows a fluctuating state, it gradually converges with time and finally converges to the central point.

\section{Conclusions}

This paper uses evolutionary game theory to explore the strategic choices of the interaction between the government and the informal recycling channel of electric vehicle batteries group. It is found that the evolutionary game model does not have an evolutionary stability strategy under the fixed punishment strategy. Then, the dynamic punishment optimization model is proposed, so that an evolutionary stability strategy emerges in the optimized system, which effectively suppresses the fluctuations in the evolution. When the initial transformation upgrading strategy of the informal recycling channel of electric vehicle batteries group is different, the performance is converged to different equalization values. Increase the upper limit of punishment, the probability of the informal recycling channel of electric vehicle batteries group choosing the transformation upgrading strategy increases.

Based on the above research conclusions, this paper proposes the following management implications. (1) Formulate policies, improve recycling management measures, and gradually improve the support system for power battery recycling. Increase subsidies for formal recycling channels and severely punish informal recycling channels. (2) Learn from the successful experience of developed countries and introduce third-party inspection agencies to assist in management. (3) Relevant enterprises should fulfill the responsibility of electric vehicle batteries, ensure the effective use of power storage batteries and environmental protection, and form a closed-loop management system. (4) Establish a power battery traceability information system to realize the source of power battery can be checked, the direction can be chased, the node can be controlled, and the responsibility can be investigated.

In the research of dynamic punishment mechanism, this paper does not consider the irrational factors of both sides of the game. The next step is to sort out the irrational factors of the two sides of the game under the dynamic punishment mechanism and analyze the impact of the game, and then propose a governance framework of dynamic punishment mechanism. Meanwhile, the simulation of this paper is carried out under the condition of numerical simulation, and the next step can be analyzed in the empirical direction.

Acknowledgements. This paper is supported by MOE (Ministry of Education in China) Project of Humanities and Social Sciences (19YJC630043), National Natural Science Foundation of China (J1824031), the Fundamental Research Funds for the Central Universities (B18RC00070) and Beijing Municipal Bureau of Economy and Information Technology Funds (T17M00070). We appreciate their support very much.

\section{REFERENCES}

[1] Capon, A., Gillespie, J., Rolfe, M., Smith, W. (2015): Perceptions of risk from nanotechnologies and trust in stakeholders: a cross sectional study of public, academic, government and business attitudes. - Bmc Public Health 15: 1-13. 
[2] Du, J., Li, Q., Qiao, F., Yu, L. (2018): Estimation of vehicle emission on mainline freeway under isolated and integrated ramp metering strategies. - Environmental Engineering and Management Journal 17(5): 1237-1248.

[3] Friedman, D. (1991): Evolutionary games in economics. - Econometrica 59: 637-666.

[4] Friedman, D. (1998): On economic applications of evolutionary game theory. - Journal of Evolutionary Economics 8: 15-43.

[5] Giovanni, P. D., Zaccour, G. (2014): A two-period game of a closed-loop supply chain. European Journal of Operational Research 232: 22-40.

[6] Gong, D., Tang, M., Liu, S., Xue, G., Wang, L. (2019): Achieving sustainable transport through resource scheduling: a case study for electric vehicle charging stations. Advances in Production Engineering \& Management 14(1): 65-79.

[7] Gu, H., Liu, Z., Qing, Q. (2017): Optimal electric vehicle production strategy under subsidy and battery recycling. - Energy Policy 109: 579-589.

[8] Hao, H., Qiao, Q., Liu, Z., Zhao, F. (2017): Impact of recycling on energy consumption and greenhouse gas emissions from electric vehicle production: the China 2025 case. Resources, Conservation and Recycling 122: 114-125.

[9] Hong, I., Yeh, J. (2012): Modeling closed-loop supply chains in the electronics industry: a retailer collection application. - Transportation Research Part E 48: 0-829.

[10] Li, L., Zhai, L., Zhang, X., Lu, J., Chen, R., Wu, F., Amine, K. (2014): Recovery of valuable metals from spent lithium-ion batteries by ultrasonic-assisted leaching process. Journal of Power Sources 262: 380-385.

[11] Li, X., Mu, D. (2018): Recycling price decision and coordinated mechanism of electric vehicle batteries closed-loop supply chain. - Soft Science 5: 1242-129.

[12] Liu, S., Gong, D. (2014): Modelling and simulation on recycling of electric vehicle batteries - using agent approach. - International Journal of Simulation Modelling 13: 7992.

[13] Ma, Z., Hu, S., Dai, Y. (2016): Decision models for a closed-loop supply chain with hybrid sale collection channels for electrical and electronic equipment under government regulations. - Chinese Journal of Management Science 24: 82-90.

[14] Ordoñez, J., Gago, E. J., Girard, A. (2016): Processes and technologies for the recycling and recovery of spent lithium-ion batteries. - Renewable \& Sustainable Energy Reviews 60: 195-205.

[15] Savaskan, R. C., Wassenhove, S. L. (2006): Reverse channel design: the case of competing retailers. - Management Science 52: 1-14.

[16] Savaskan, R. C., Bhattacharya, S., VanWassenhove, L. N. (2004): Closed-loop supply chain models with product remanufacturing. - Management Science 50: 239-252.

[17] Tan, Q., Li, J. (2015): Recycling metals from wastes: a novel application of mechanochemistry. - Environmental Science \& Technology 49: 5849-5861.

[18] Turner, J. M., Nugent, L. M. (2016): Charging up battery recycling policies: extended producer responsibility for single-use batteries in the European Union, Canada, and the United States. - Social Science Electronic Publishing 20: 1148-1158.

[19] Wang, W., Wu, Y. (2017): An overview of recycling and treatment of spent LiFePO 4 batteries in China. - Resources, Conservation and Recycling 127: 233-243.

[20] Wang, Y., Chang, X., Chen, Z., Zhong, Y., Fan, T. (2014): Impact of subsidy policies on recycling and remanufacturing using system dynamics methodology: a case of auto parts in China. - Journal of Cleaner Production 74: 161-171.

[21] Xu, J., Thomas, H. R., Francis, R. W., Lum, K. R., Wang, J., Liang, B. (2008): A review of processes and technologies for the recycling of lithium-ion secondary batteries. Journal of Power Sources 177: 512-527.

[22] Yu, H., Xie, Y., Zhang, T. (2014): Technical progress on power batteries recovery for electric vehicle. - The Chinese Journal of Non-ferrous Metals 24: 448-460. 
[23] Zhao, F., Liu, Z., Hao, H., Zhao, S., Zhang, X., Li, J. (2016): Analysis of China's strategy for a stronger automotive country and its implementation pathway. - Forum on Science and Technology in China 8: 45-50.

[24] Zhang, S., Zhang, M., Yu, X., Ren, H. (2016): What keeps Chinese from recycling: accessibility of recycling facilities and the behavior. - Resources Conservation \& Recycling 109: 176-186. 